Татьяна МОРЕЙ

\title{
ОХРАНА МАТЕРИНСТВА И ДЕТСТВА В УКРАИНСКИХ ГУБЕРНИЯХ РОССИЙСКОЙ ИМПЕРИИ В ПЕРВОЙ ПОЛОВИНЕ ХІХ В.: НОВЫЕ ПОДХОДЫ И АЛЬТЕРНАТИВНЫЕ РЕШЕНИЯ
}

\author{
THE PROTECTION OF MOTHER AND CHILD IN THE UKRAINIAN \\ PROVINCES OF THE RUSSIAN EMPIRE DURING THE FIRST HALF OF THE \\ $19^{\mathrm{TH}}$ CENTURY: NEW APPROACHES AND ALTERNATIVE SOLUTIONS
}

\begin{abstract}
Several documents preserved in the archives of Kyiv (Ukraine) investigate the origins of mother and child protection in the Ukrainian lands that were part of the Russian Empire. This paper analyses, with reference to the first half of the $19^{\text {th }}$ century, the historical, social and legal circumstances that influenced the establishment of the institution of motherhood and childhood protection. It also details several questions, important for our own times, such as the functioning of medical districts, the funding of medical institutions, the organisation of doctors and paramedics, the relations between doctors and local administration, etc.
\end{abstract}

Keywords: mother and child protection, medical aid, regulatory support, Kyiv Medical Council.

Одна из стратегически важных и приоритетных задач европейских государств в области здравоохранения - обеспечение жизни и здоровья матерей и детей. Основой этого направления является рождаемость, здоровье новорожденных детей, безопасность родов, предупреждение материнской и младенческой смертности. Среди множества факторов, влияющих на здоровье матери и ребенка, особая роль принадлежит социальным. Поэтому состояние женщины-матери и ребенка является индикатором социального благополучия населения и зрелости государства.

*ДВНЗ «Переяслав-Хмельницький державний педагогічний університет імені Григорія Сковороди», Переяслав, Україна; tetianamorei@gmail.com

Analele Universităţii „Dunărea de Jos” din Galaţi, Seria 19, Istorie, tom XVIII, 2019, pp. 17-

25. 
Становление и развитие системы охраны здоровья матери и ребенка насчитывает не одно столетие. В первой половине XIX в. получает развитие законодательство, формируется сеть медицинских учреждений, генерируются знания и распространяются в социуме, расширяется пространство профессиональных коммуникаций врачей. Ведущей формой международного сотрудничества были научные командировки, во время которых, отечественные ученые не только изучали зарубежный опыт образовательной и научно-исследовательской деятельности, но и представляли собственные достижения и открытия, принципы общеевропейской культуры. В первой половине XIX в. достаточно мало было литературы по акушерству и гинекологии. В основном пользовались иностранной литературой, а также изданиями на русском языке Н. Амбодика-Максимовича, В. Рихтера и В. Грубера. Некоторые клинические сообщения появлялись также в анатомических работах ${ }^{1}$. Специальные дисциплины, такие, как акушерство и гинекология, детские болезни стали развиваться во второй половине XIX в.

Вопросы о состояние охраны здоровья матери и ребенка исследуют такие ученые, как Е. Боряк ${ }^{2}$, К. Ченкова ${ }^{3}$, А. Третьяк ${ }^{4}$, А. Авдеев ${ }^{5}$. Авторы рассматривают направления подготовки медицинского персонала, анализируют демографическую ситуацию, причины детской смертности. В докторской диссертации Е. Боряк анализирует становлении института акушерства в украинском обществе, роль повивальных бабок при рождении детей. По мнению автора, повивальные бабки и были первичными носителями акушерско-гинекологических знаний ${ }^{6}$. К. Ченкова исследует проблемы зарождения охраны материнства и детства в контексте анализа гражданского

${ }^{1}$ Будко А.А. История медицины Санкт-Петербурга ХІХ-начало XX в.( Спб.: НесторИстория, 2010), 400 c.

${ }^{2}$ Боряк О.О. "Інститут акушерства $і$ постать повитухі в традиційній культурі україниів: історія, ритуал, міфологія":(дис. докт. іст. наук, Інститут мистецтвознавства, фольклористики та етнології м. М. Рильського НАК України, 2010)

${ }^{3}$ Ченкова К. П. ”Правова охорона материнства та дитинства за ичивільним (цивільносімейним) законодавством в украӥнських губерніях Російської імперї (XIX cm. - 1917 р.)", Науковий вісник міжнародного гуманітарного університету. Серія: Юриспрудениія, 12(2014):41-45.

${ }^{4}$ TretyakAnna S. "History of Maternity and Infancy in Zemsky Period (Based on the Central Chernozem (Black Earth Region) Fieles)", BylyeGody, 35(2015):94-99,: http://oaji.net/articles/2015/7-1426264116.pdf.

${ }^{5}$ Авдеев А. "Младенческая смертность и история охраны материнства и детства в России и СССР", Историческая демография 1(2010):13-72.

${ }^{6}$ Боряк "ІІнститут акушерства і постать повитухі в традиційній культурі украйниів: історія, ритуал, міфологія", 1-379 
(семейного) законодательства, действовавшего в украинских губерниях Российской империи (XIX в. - 1917 гг.) ${ }^{7}$.

Анализированные нами нормативно-правовые акты дают основания утверждать, что к середине XIX в. вопросы охраны материнства и детства были очерчены в правовом поле, хотя это были слабо систематизированы правовые акты, которые лишь частично обеспечивали выживание и развитие ребенка.

В 1797 г. в украинских губерниях, в том числе и Киевской, были организованы врачебные управы, которые, по сути, заведовали системой гражданской и военной медицины. К этому периоду вопросами здравоохранения занималась общая администрация. Врачебная управа состояла с оспенного комитета, карантинных учреждений, управления аптек, различных лечебных учреждений и минеральных вод. Врачебной управе подчинялись уездные и местные врачи, аптекарские ученики, бабки-повитухи и все лица, которые занимались свободной медицинской практикой ${ }^{8}$. Чиновники управы принимали экзамены у фармацевтов, бабок-повитух и студентов духовных училищ, контролировали продажу аптекарских материалов, состояние лечебных заведений, лечение и содержание больных в больницах; осуществляли топографическое описание губернии ${ }^{9}$.

В уездах и городах медицинскую помощь роженице оказывали врачакушер и повивальная бабка. Одной из основных задач городского акушера было предоставление родовспоможения в тяжелых родах и при необходимости оперативное вмешательство. Акушеры должны были контролировать работу повивальных бабок, особенно тех, которые недобросовестно относились к своим обязанностям. Несмотря на материальное положение роженицы, акушер обязан был сделать все от него зависящее для успешного проведения родов ${ }^{10}$. Ему запрещалось требовать подарки и деньги от малообеспеченных лиц. За нарушение этой нормы закона, акушера могли лишить звания. Согласно закону за помощь в тяжелых родах врач-акушер мог получить вознаграждение в 1 руб. 50 коп. серебром ${ }^{11}$.

Особого внимания заслуживает состояние повивального дела в уездах губерний. 30 января 1797 № 77773 был утвержден законопроект «Об

\footnotetext{
${ }^{7}$ Ченкова, Правова охорона материнства, 43-44

${ }^{8}$ Свод законов Российской Империи (далее СЗРИ)Т. ХІІІ., Ч. 3.: 1857 2., Ст. 23,(1857)

15 том.( СПб.: Тип. Второго Отделения Собственной Е.И.В. Канцелярии, 1857-68)

/Свод законов Российской Империи издание: 1857 г. [в 15 m.]

${ }^{9}$ Маркус Л.М. "Краткое руководство для врачей к познанию Российских законов, учреждений и государственной службы” "(ППб.: Эдуарда Праца, 1843), 89-90

${ }^{10} \mathrm{C} 3 Р И$, Сm.149-53,(1857),c.28

${ }^{11}$ Маркус, Краткое руководство для врачей..., 76
} 
определении повивальных бабок не только в городах губернских, но и в уездных, с назначением им жалования». В законопроекте отмечалось, что в губерниях и уездах не было необходимого количества обученных повивальных бабок, что нередко приводило к смерти рожениц и их малышей. Врачебная коллегия отмечала, что повивальные бабки должны были быть не только в губернских, но и в уездных городах: в каждом губернском - старшая и младшая, которые оказывали помощь не только населению города, но и уезда ${ }^{12}$. Хотя, были случаи, когда нужна была помощь уездного врача, особенно при патологических болезнях и других сложных случаях. Повивальные бабки должны были составлять ежемесячные отчеты и направлять их во врачебную управу, сообщая о количестве принятых родов.

В соответствии со ст. 479 Врачебного устава звание повивальной бабки могла получить женщина не моложе 20 и не старше 45 лет ${ }^{13}$. При зачислении на службу повивальная бабка должна была прослушать полный курс лекций об оказании помощи роженицам в лечебных учреждениях. Она была обязана предоставить свидетельство о принятии ею не менее трех родов в присутствии врача, и указать, с каким успехом прошли эти роды. После этого, она должна показать свое мастерство в ходе родов в акушерской клинике ${ }^{14}$. В 1830 г. Киевская врачебная управа взяла подписки с повивальных бабок Киевской губернии, запрещая им заниматься акушерской практикой, если они не сдали соответствующие экзамены и не получили на это право ${ }^{15}$.

Закон определял, что повивальная бабка обязана была уметь читать и писать на одном из применяемых в Европе языков. Должна быть человечной, доброй, скромной, трезвой, иметь навыки в акушерском деле. Повивальная бабка не имела права лечить другие болезни, кроме женских и детских, и то только в тех случаях, когда не было врача. Ей запрещалось оперировать, за исключением перерезания пуповины. В особо тяжелых родах повивальная бабка должна была вызвать акушера из ближайшей врачебной управы или уездного врача и объяснить им весь ход родов. После родов, она 10 дней посещала роженицу и имела право получить за эту работу 1 руб. 50 коп. серебром. Малообеспеченным слоям населения оказывала помощь бесплатно ${ }^{16}$.

\footnotetext{
${ }^{12}$ Полное собрание законов Российской Империи(далее ПСЗРИ). Т. 24, №. 17773. c.312.(1797) (СПб.: Тип.ІІ Отд-ния. Собствен. Канцелярии Его Имп. Величества)

${ }^{13}$ СЗРИ, Сm.479,(1857),c.90

${ }^{14}$ СЗРИ,Ст.480-81,(1857),c.90

${ }^{15}$ Центральний государственный исторический архив Украины, г. Киеве (далее ЦГИАК Украины). ф. 533,д.639. л.3

${ }^{16}$ Маркус, Краткое руководство для врачей...,63-4
} 
Когда рождался ребенок с проблемами со здоровьем, то повивальная бабка должна была сохранить ему жизнь, но о таких случаях незамедлительно и подробно сообщить городскому акушеру или во врачебную управу. При тяжелых родах или даже смерти роженицы также сообщала акушеру или врачу и вместе с ним могла проводить хирургическую операцию для сохранения жизни младенца ${ }^{17}$. Во Врачебном уставе 1857 г. в ст. 184 было указано, что повивальная бабка не имела права прерывать беременность по просьбе женщин. Кроме того, о таких случаях она должна была докладывать начальству. Повивальная бабка обязана научить роженицу ухаживать за ребенком, а в случаях небрежного ухода матерью за новорожденным (в частности, пьянства родителей и т.п.) - сообщать об этом начальству ${ }^{18}$.

В исследуемый период прослеживается тенденция формирования нормативно-правового регулирования охраны детства, что обеспечило бы полноценную жизнь ребенка. Закон предусматривал сохранение жизни детей с умственными и физическими недостатками; принятие определенных мер в случае недобросовестного выполнения родительских обязанностей и, что самое главное - запрет абортов (прерывание беременности по просьбе женщины).

Государство, также заботилась о лечении и питании детей. В 1855 г. при Кирилловской больнице было открыто детское отделение, питание в котором обеспечивало государство. Медицинский совет по вопросам питания, поделил возраст детей на 2 периода: 1) от 2 до 10 лет, 2) от 10 до 16 лет, а по использованию больничной одежды, на три: 1) от 2 до 5 лет, 2) от 5 до 10 лет, 3) от 10 до 16 лет. Взрослое питание было разделено на четыре особые порции: простую, среднюю, слабую и кисельную ${ }^{19}$, а детское питание - на шесть особых порций: простую, среднюю, слабую, молочную, кисельную, экстренную. На завтрак детям давали овсяную крупу и масло. На обед: в ординарную порцию входил ржаной хлеб, перловая, овсяная или гречневая крупы, говядина для супа, соль; в среднюю - ржаной хлеб, телятина, соль; в слабую- пшеничный хлеб, крупа овсяная или чернослив с яблоками, овсяный суп с телятиной, соль; в молочную- хлеб пшеничный или ржаной, молоко; в кисельную- пшеничный хлеб, мука овсяная, мед; в экстренную - хлеб пшеничный, куриное мясо, манная крупа, соль. Размер порций зависел от возраста больных детей. К такому рациону постоянно вносили изменения. Например, чиновниками Медицинского совета был сделан вывод, что

\footnotetext{
${ }^{17}$ СРРИ, Сm.179-80,(1857),c.32

${ }^{18} \mathrm{C} 3 Р И$, Сm.184-88,(1857),c.33

${ }^{19}$ ПСЗРИ. Т.30, №. 23967. с. 1257. (1809)
} 
гороховый суп нужно исключить из рациона, поскольку горох содержит в себе мучнистые трудноусваиваемые элементы, что плохо влияло на пищеводные органы и могло даже привести к развитию золотухи. Горох был исключен даже с табеля питания в лечебных учреждениях гражданского ведомства. Масло также было исключено из ординарной порции, поскольку служащие считали, что использована в супе говядина первого сорта достаточно сытная, и масло не улучшит бульон $\mathrm{c}$ хорошей говядины. В зависимости от предпочтений больного молочная порция могла быть заменена кисельной ${ }^{20}$.

В циркуляре от 20 июня 1855 № 149 были разработаны правила приобретения одежды и больничных вещей для малолетних больных. Уставом лечебных учреждений определялся срок годности этих вещей. Документ предусматривал, что кровати и постельное белье должны соответствовать возрасту ребенка. Матрасы и подушки набивали соломой или волосом ${ }^{21}$.

Архивные материалы содержат наименование и количество вещей, необходимых для одного ребенка в соответствии с возрастной группой. Например, в детское отделение Кирилловской больницы детям от 2 до 5 лет закупали 18 шт. брюк из хлопка с вышивкой; детям от 5 до 10 лет - 105 шт. Эту одежду использовали 2 года. Для возрастной категории детей от 10 до 16 лет покупали 45 юбок из фламского полотна, столько же шейных косынок из белого коленкора, халаты из фламского полотна, носки зимние шерстяные, летние хлопчатобумажные, кожаные туфли, брюки. Для постельного белья использовали простыню и пододеяльник из фламского полотна, одеяло из разного фабричного сукна, простыню для подшивки одеял, наволочки, полотенца ${ }^{22}$.

Перед поступлением в учебные заведения проводились медицинские осмотры, поскольку проблемы со здоровьем имела и студенческая молодежь. Жизнь больного зависела от профессионализма врача. Следует отметить, что значительно влияло на состояния здоровья студентов чрезмерное употребление алкоголя и табакокурение. Среди заболеваний студенчества имели место инфекционные и венерические болезни, тиф, заболевания желудка, простуда, болезни глаз и тому подобное. От многих болезней не было лекарств, поэтому наблюдалась высокая смертность. Для спасения здоровья студентов коммерческие учреждения дважды в неделю организовывали профилактические осмотры, покупали медицинские инструменты и лекарства. Больные студенты могли получить помощь и в

${ }^{20}$ ЦИИАКУкраины.ф.442, оп.650. л. 1-3

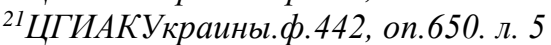

${ }^{22} Ц$ ЦИАКУкраины.ф. 442 , оп.650. л.7 
университетских клиниках. Тяжелобольные пациенты направлялись в городские клиники, где содержались за счет вузов. ${ }^{23}$.

Молодежь лечилась в больнице при университете Св. Владимира. Студенческая больница располагалась в помещении университета и была рассчитана на 15 коек. В университетской больнице студенты лечились за свой счет.

В отчете врача при университете Св. Владимира И. Щербины отмечено, что общее количество студентов университета в период с 1 января 1849 г. по 1 января 1864 г. составляло 11633 человек и с которых заболело 2213 студентов. По нашим подсчетам в университетской больнице лечилась $1 / 5$ часть студенчества. С 2213 человек выздоровело 2180, умерло - 33. От бугорчатой чахотки легких умерло 20 человек, тифа - 6, холеры, брайтовой болезни, гнойного заболевания грудной клетки, апоплексии легких, болезни сердца, воспаление брюшины, воспаления внутренней оболочки сердца - по одному человеку ${ }^{24}$.

Большинство студентов поступало в больницу с катаральной лихорадкой, которая по мнению врача И. Щербины не была сложной в лечении и не сопровождалась опасными осложнениями. Эту болезнь лечили полосканием горла. Осложнения от болезни могли появляться, в большей степени, во время эпидемии гриппа. Количество больных в больнице увеличивалось в период холерных эпидемий, а именно в 1853 г. и 1855 г. Наименьшее количество больных было в 1859 г. Для лечения больных холерой в помещении университета открыли особое холерное отделение больницы, которое было обеспечено всем необходимым. На помощь врачу назначались два помощника из числа студентов медицинского факультета, которые по очереди постоянно находились в отделении. Наибольшее количество больных тифом было в 1853 г., а меньше всего заболело - в 1852 г. Большинство случаев заболеваемости тифом была перед холерной эпидемией. Болели, в большей степени, студенты медицинского факультета, которые посещали военный госпиталь ${ }^{25}$. За 15 лет описан один случай оперативного вмешательства. Больной страдал болезнью Lythiasis (камни в мочевом пузыре). Лечение минеральной водой было малоэффективным, и тогда

\footnotetext{
${ }^{23}$ Казьмирчук М.Г. Сочіально-економічний розвиток Київської губернії (18611917pp.)(К.: Логос, 2011), 259-60

${ }^{24}$ Материаль для медицинской статистики г. Киева. Краткий отчет о больнице студентов университета Св. Владимира с 1849 по 1864 год врача при университете И. Щербины (К.: Университетская типография, 1865 ), 2

${ }^{25}$ Материалы для медииинской статистики ...,5-6
} 
профессор В. Караваев успешно провел операцию, удалив камень, размером в лесной орех ${ }^{26}$.

Для медицинской статистики вели специальный учет всех больных студентов. В соответствии с указом Медицинского департамента МВД от 25 января 1843 г. Киевская врачебная управа обязана была прислать 10 печатных бланков сведений, которые были сформированы Медицинским советом, и в которых содержались сообщения о количестве больных в империи, количестве больных при университете Св. Владимира, Киевских гимназиях, дворянских уездных училищах. По Киевской губернии такие сведения, в установленной форме, должны были ежемесячно отправлять в управу. Отдельно указывалась информация о больных, лечившихся в больницах, и больных, которых лечили частные врачи. Медицинские работники при учебных заведениях также должны были указывать в сведениях дополнительную информацию об особых видах болезней (вносились по усмотрению врача прописными буквами), о больных, которые консультировались у нескольких специалистов, о больных, которые перестали лечиться до полного выздоровления, об инфекционных лихорадочных болезнях (о каждом особом случае отдельно). С целью дальнейшего использования этих материалов в медицинской статистике желательно, чтобы эти сведения сопровождались данными об эпидемической конституции, об эпидемических условиях появления некоторых болезней (которые зависели от климата, местоположения, образа жизни больного), об успехах или недостатках в борьбе с болезнями ${ }^{27}$.

Такие формы бланков стоили 3 коп. серебром за экземпляр. Архивные данные свидетельствуют, что врач второй Киевской гимназии Багежский заплатил за два бланка 6 коп. серебром. Другие учреждение во врачебную управу таких средств не направляли. Поэтому управа просила попечителя Киевского учебного округа за 8 бланков прислать 24 коп. серебром для отправки их в медицинский департамент ${ }^{28}$.

В 1850 г. для облегчения ежегодной отчетности и предоставления своевременной информации форма бланков была изменена. Период отчетности устанавливался от первого до первого декабря ежегодно. Врачебная управа обязывала составлять такие документы профессоров медицинского факультета при университете Св. Владимира и студенческой больнице, врачей при институте благородных девиц, первой и второй гимназия ${ }^{29}$. Такие же бланки сведений использовали и в последующие годы, о

\footnotetext{
${ }^{26}$ Материаль для медицинской статистики ...,11

${ }^{27}$ ЦИАК Украиньл. ф. 707,on .29.л.10-11

${ }^{28} Ц$ ИАК Украины. ф. 707,on .29.л.19

${ }^{29}$ ЦИАК Украиньл. ф. 707, оn .548.л. 1-3
} 
чем свидетельствуют архивные материалы за 1858 г. Документы свидетельствуют о возложении обязанностей на медицинских служащих учебных заведений ежегодно направлять в Киевскую врачебную управу сообщения о наличие больных ${ }^{30}$.

Таким образом, проанализированные архивные источники и нормативно-правовые акты дают основания утверждать, что в первой половине XIX в. в украинских губерниях, входивших в состав Российской империи, начали формироваться механизмы защиты материнства и детства. Существенными негативными факторами в вопросах охраны материнства и детства были незавершенность систематизации медицинского законодательства, малоэффективное функционирование лечебных учреждений, несовершенство медико-социальных мероприятий, обеспечивающих условия для рождения здорового ребенка, предупреждения и лечения болезней у женщин и детей.

${ }^{30}$ ЦИАК Украины. ф. 707,on .405.л.2-3. 